\title{
The Study of the Mechanical Properties of Small Tubes Made from Oxide Dispersion Strengthened Steel by Using the Ring Tension Tests
}

\author{
ALEXANDRU NITU', MARIOARA ABRUDEANU2,2*, VASILE RADU ${ }^{1}$ \\ ${ }^{1}$ Institute for Nuclear Research Pitesti, 1 Campului Str., 115400, Mioveni, Arges, Romania \\ 2 University of Pitesti, 1 Targul din Vale Str., 110040, Pitesti, Arges, Romania \\ ${ }^{3}$ Technical Science Academy of Romania, 26 Dacia Blvd., Bucharest, Romania
}

The paper aims to investigate the mechanical properties of tubes having a small diameter and made from new steels called ODS steels Oxide Dispersion Strengthened steels). These new materials are candidate materials for fuel claddings in the generation IV reactors. This work contributes to original results to the experimental program carried out by RATEN ICN Pitesti in the framework of the FP7 European MatISSE Project(Materials' Innovations for a Safe and Sustainable nuclear în Europe). The experimental method used for the investigating of the mechanical properties of ODS steel tubes is a non-standard method, known as Ring Tension Test (acronym - RTT). It is recommended for the mechanical testing of tubes with thinner walls and reduced inner diameter. The main advantage of $R T T$ is that the tested sample maintains the initial geometry of the component from which has been made. For the experimental RTT tests, the ODS tubes were provided by MatISSE Project participant, CEA France. Tubes are in two different compositions: Fe-9Cr ODS and Fe-14Cr ODS. For a better understanding of the ODS mechanical properties, some further investigation on the scanning electron microscopy is carried out.

Keywords: gen. IV reactors; mechanical properties; ODS steels; Ring Tension Test

The structural integrity of nuclear components is the main task in the research area for the generation IV of the nuclear reactors. Its objective is to ensure a demanding safety of functioning and operation for the nuclear facilities. Also, ithas a large applicability from the design and manufacturing stages until the last phase - decommissioning. In the scientific literature, in addition to the classical, standardized (ASTM) experimental mechanical tests, there are in use some new non-standardized tests. This is due to the fact that determination of the mechanical properties by standard methods processes of sample preparation resulting in a change of the actual geometry of the component, and is introducing additional residual stresses during the manufacture of the samples. Thus, the mechanical characterization of the fuel cladding tubes with smaller diameter is recommended to be done by using tensile testmethod with ring type samples. This testing method is known in the literature as the Ring Tension Test(RTT). This method is recommended to evaluate mechanical properties of materials candidate for nuclear fuel cladding tubes, in generation IV reactors, for their reduced diameter which makes impossible to obtain a standard flat sample in the transverse direction withoutsignificant residual stresses value.

\section{Experimental part}

The material under investigation is an innovative material, candidate as the structural material in gen IV reactors, called ODS steel - Oxide Dispersion Strengthened (Fe-9Cr ODS martensitic steel and Fe-14Cr ODS ferritic steel). The ODS tubes for the experimental investigation has been provided by CEA France, that was a partner in the framework of FP7 European MatISSE Project. The main ODS steel characteristic consists of the reinforcing the ferritic/martensitic steels by a homogeneous distribution of nano-grained oxides (eg. yttrium oxide- $\mathrm{Y}_{2} \mathrm{O}_{3}$ ) in the steel matrix. The addition of oxides induces the dislocation movement blockage and this promotes a remarkable improvement of the mechanical properties. These materials are characterized by a very good creep resistance under high temperatures, good corrosion properties and low swelling under irradiation [1, 2]. High creep resistance is provided by a homogeneous distribution of the nanometric oxides and can be explained as a limiting strain and a much higher rupture time (fig. 1) [3-5].

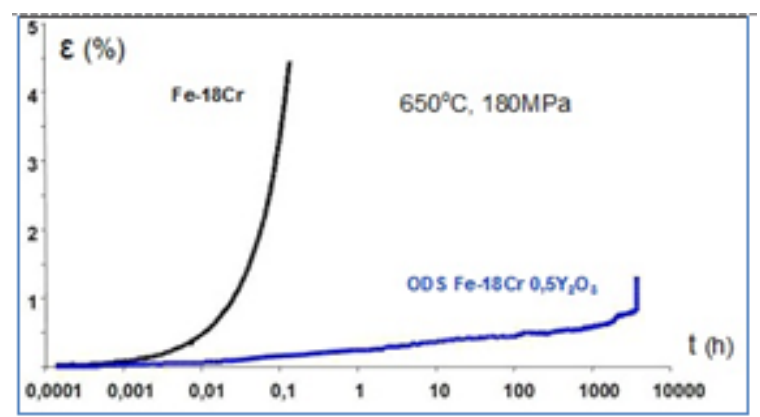

Fig.1. Creep behavior of ODS steels compared with no oxides addition steels [3]

Metallographic analyses performed on both materials shows the similar metallographic images. However, some precipitates are observed on both materials and probably are $\mathrm{TiO}_{2}$ particles (fig. 2) [6-8].

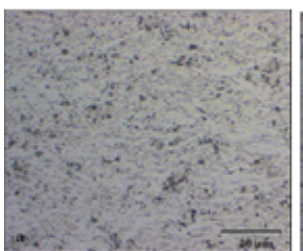

a)

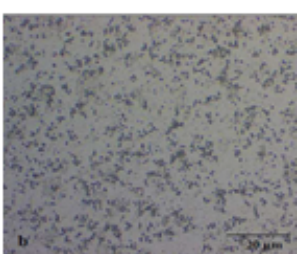

b)
Fig. 2. Metallographic aspects: a) Fe-9Cr ODS b) Fe-9Cr ODS [9]

Ring Tension Tests: the non-standardized tensile tests

The ring tension test is a test for the determining material properties onlyin the hoop direction of atube. The hoop direction properties are needed fortubular structural components which are known to have anisotropic mechanical properties due to the fabrication process $[10,11]$. The Ring Tension Test (RTT) is a non-standardized testing method, and the principle of the test is to produce a mechanical stress in the circumferential

\footnotetext{
*email: abrudeanu@gmail.com; Phone: (+40)7405054086
} 
Fig. 3. The loading scheme versus gauged sections

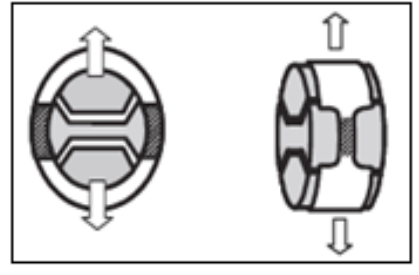

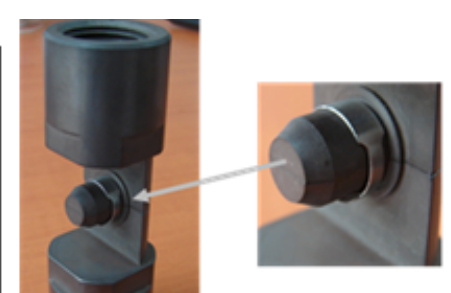

Fig. 4. Ring tension device (loading grips and specimen) direction of the cylindrical sample through a radial tensile loading (fig. 3 and fig. 4).

The tensile tests were carried out on the hydraulic mechanical testing machine Walter + Bai at room temperature and temperature of $500{ }^{\circ} \mathrm{C}$ with a crosshead speed of $0.017 \mathrm{~mm} / \mathrm{s}[12,13]$. Note some advantages of this type of test:

-The RTT method could use the smaller specimens compared with those used in the burst tests;

-The specimen geometry of the ring specimen is relatively easy to be prepared;

-The procedure could be also applicable to irradiated materials.

The specimens used for the non-standard mechanical tests are the RTT type samples. They are characterized by two narrowing sections positioned diametrically opposed (fig. 5).
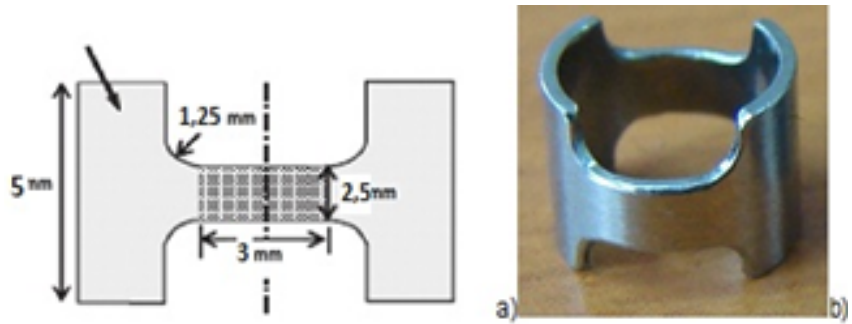

Fig. 5. RTT specimen: a) sketch and dimensions; b) RTT specimens

An important issue for these types of tests is the friction arising between the samples and gripping system. In order to reduce the friction coefficient, a Teflon tape was introduced between the sample and gripping system [13, 14, 15]. For all samples tested, the fracture zone is in the narrowing section, and the mechanical tests are valid (fig. 6). Atroom temperature, the fracture behaviour is similar between the two materials (fig. $6 \mathrm{~b}$ ). For tests performed at a temperature of $500^{\circ} \mathrm{C}$ one may see thatFe-14CrODS steel samples are strongly oxidized and rupture occurred on both narrowing sides (fig. 6c).

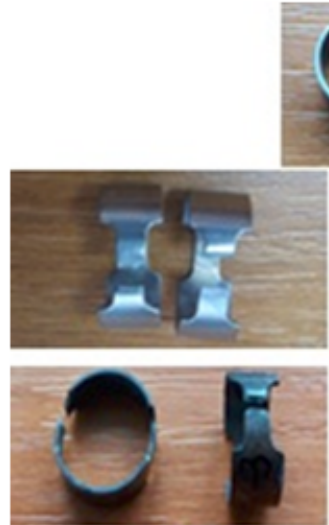

$\mathrm{Fe}-9 \mathrm{Cr}$

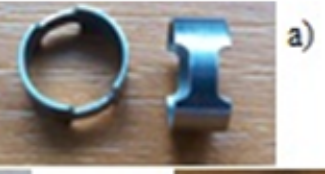

b)

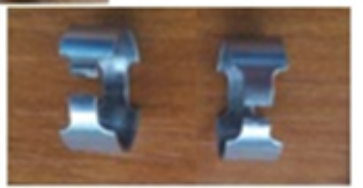

c)

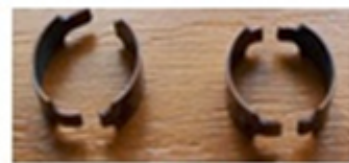

$\mathrm{Fe}-14 \mathrm{Cr}$
Fig. 6. ODS specimens: a) before testing; b) tested at $20^{\circ} \mathrm{C}$; c) tested at $500^{\circ} \mathrm{C}$

\section{Results and discussions}

In this chapter, the both materials results from RTT are discussed. The tensile behaviour of materials is displayed in figure 7 (Fe-9Cr ODS) and figure 8 (Fe-14Cr ODS) for room temperature and at $500^{\circ} \mathrm{C}$ as well.

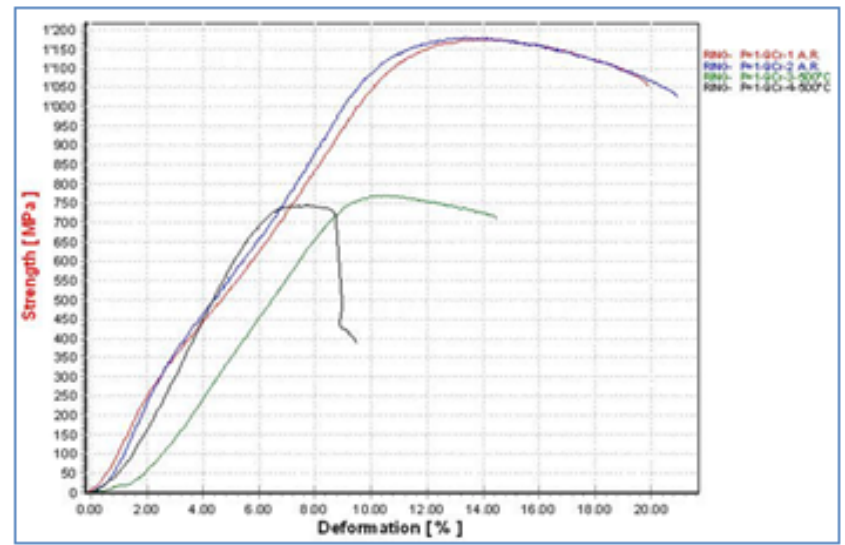

Fig. 7. The experimental tensile curves for ODS Fe-9Cr (20 and $\left.500^{\circ} \mathrm{C}\right)$

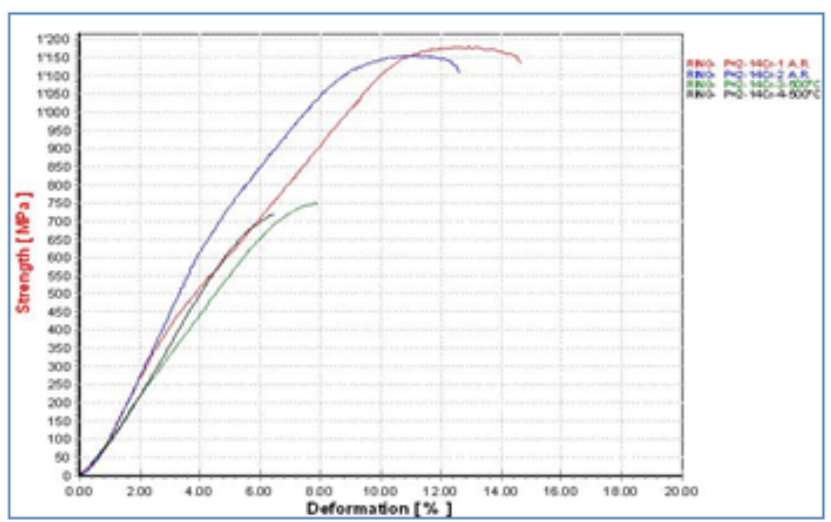

Fig. 8. The experimental tensile curves for ODS Fe- $14 \mathrm{Cr}\left(20\right.$ and $\left.500^{\circ} \mathrm{C}\right)$

Due to the test configuration and specific specimen shape, we may define here the tensile strength as Ultimate Tensile Hoop Strength (UTHS). This is, probably, the most appropriate name for the material property obtained during RTTS. Table 1 shows UTHS for both materials tested at room temperature and $500^{\circ} \mathrm{C}$.

Table 1

THE EXPERIMENTAL RESULTS FROM RTTS

\begin{tabular}{|l|l|l|}
\hline \multirow{2}{*}{ Temperatură $\left({ }^{\circ} \mathrm{C}\right)$} & \multicolumn{2}{|c|}{ UTHS (MPa) } \\
\cline { 2 - 3 } & Fe-9Cr ODS & Fe-14Cr ODS \\
\hline $\mathbf{2 0}$ & 1175 & 1179 \\
\hline $\mathbf{2 0}$ & 1179 & 1155 \\
\hline $\mathbf{5 0 0}$ & 769 & 750 \\
\hline $\mathbf{5 0 0}$ & 746 & 718 \\
\hline
\end{tabular}

The examination of the results obtained can be seen that tensile behaviour is rather the same for both ODSs and the UTHS values at $500^{\circ} \mathrm{C}$ are decreased by $20 \%$ in comparison with those at room temperature (fig. 9 and fig. 10).

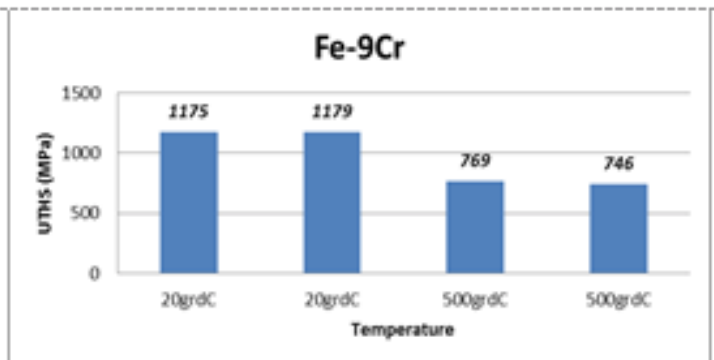

Fig. 9. UTHS for Fe-9Cr ODS versus temperature 


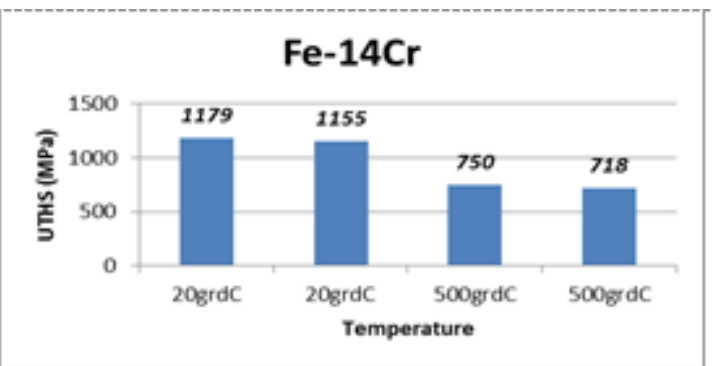

Fig. 10. UTHS for Fe-14Cr ODS versus temperature

In the same conditions of temperature, the Fe-9Cr ODS steel has a higher tensile strength than the Fe-14Cr ODS. This aspect is highlighting by the figure 11, where the UTHS average values are presented for each material.

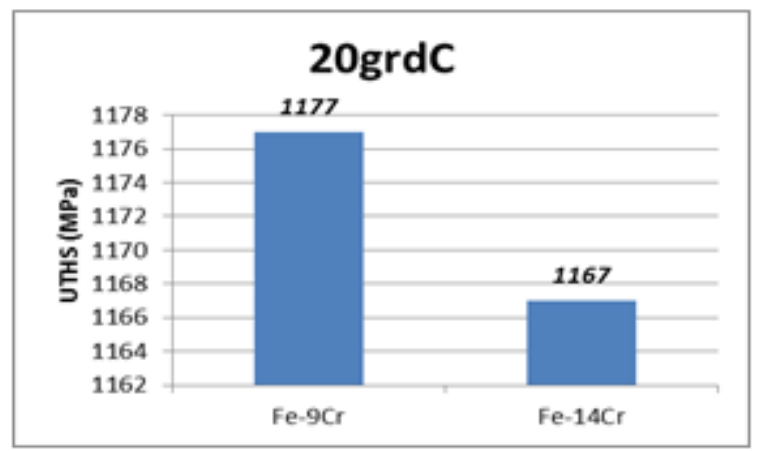

a)

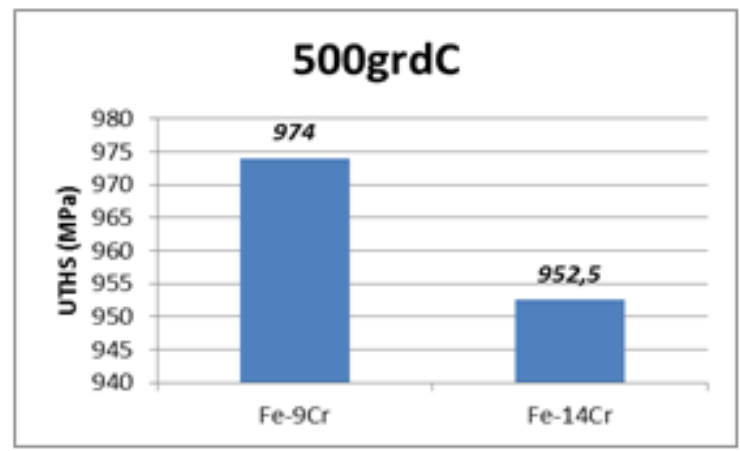

b)

Fig. 11 Comparison between materials: a) $20^{\circ} \mathrm{C}$; b) $500^{\circ} \mathrm{C}$

The morphology of the fracture surface after the RTT depends on the material and method of manufacture $[16,17]$. Figure 12 displays the aspects of fracture surfaces of two samples of Fe-9Cr ODS steel, tested at room temperature and at $500^{\circ} \mathrm{C}$. From SEM images, there is a ductile character of the fracture surface with the appearance of a slight necking. The dimples on the fracture surface are in a large number and have a spherical aspect with sizes between lim and 10im and some are relatively deep. This little ductile aspect is in concordance with tensile curve shape in the room for both temperatures. Regarding Fe-14Cr ODS steel, in figure 13 are shown the fracture surfaces for samples tested at 20 and $500^{\circ} \mathrm{C}$. The difference from the samples of Fe-9Cr ODS steel lies in the fact that the crack front has a more brittle aspect and the necking of the sample is not observed. The predominant failure mode for Fe-14Cr ODS steel is by the cleavage phenomenon with some small ductile areas where the few small and shallow dimples are grouped. Also, from the SEM images, it is noted that the laminating process, whereby the tubes have been obtained, produced different effects on these two materials. Thus, the Fe-9Cr ODS steel presents a more small and fine grain size; while Fe-14Cr ODS steel grains are more elongated. Another characteristic of fracture surfaces resulting from tensile tests on ODS steels is the appearance of delaminating. This is not yet sufficiently explained [16]. The justification would consider the elongated
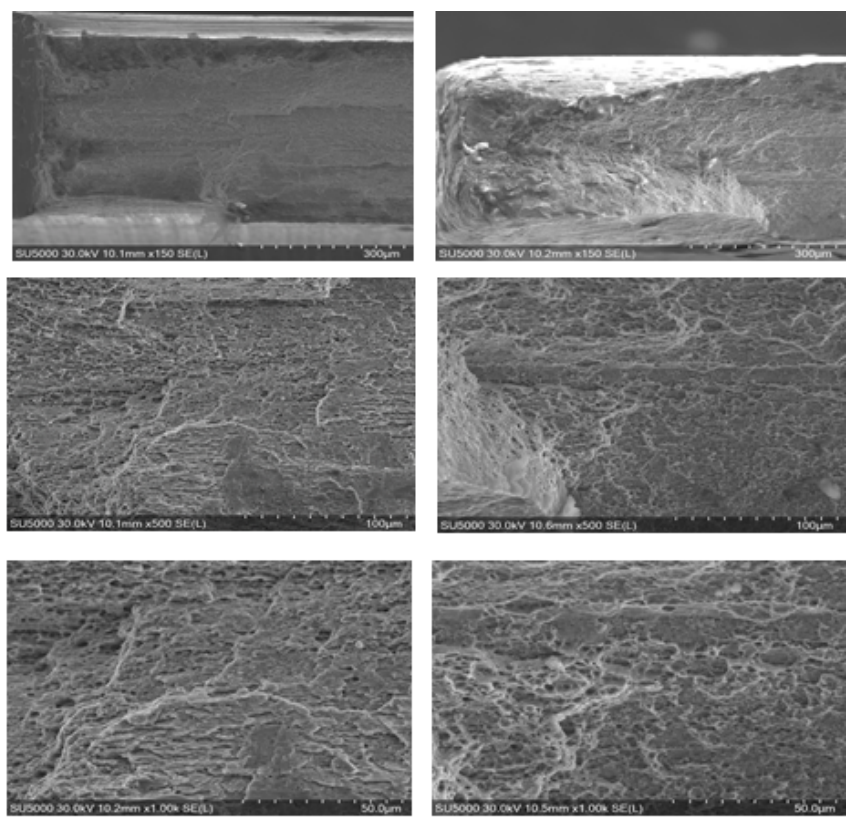

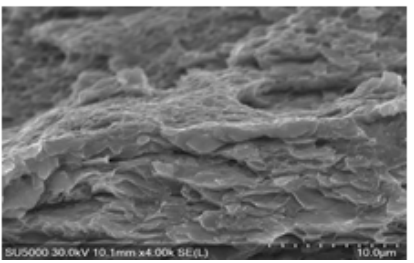

Fig. 12 SEM Fe-9Cr ODS for $20^{\circ} \mathrm{C}$
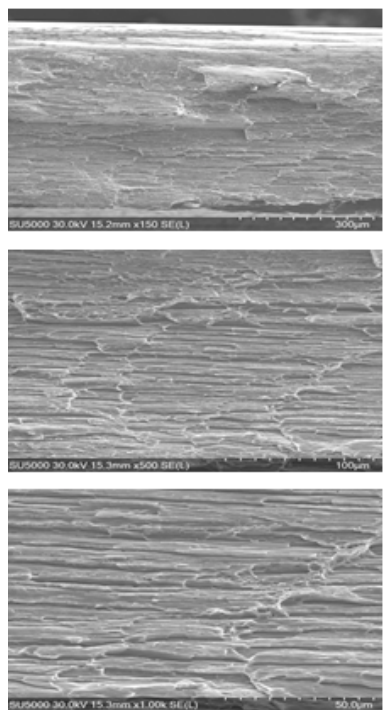

Fig. 13 SEM Fe-14Cr ODS for $20^{\circ} \mathrm{C}$

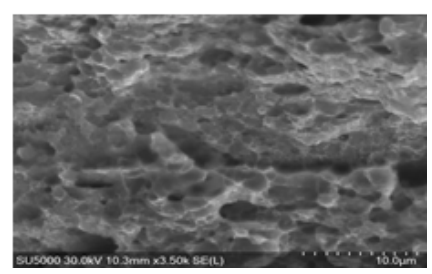

SEM Fe-9Cr ODS for $500{ }^{\circ} \mathrm{C}$
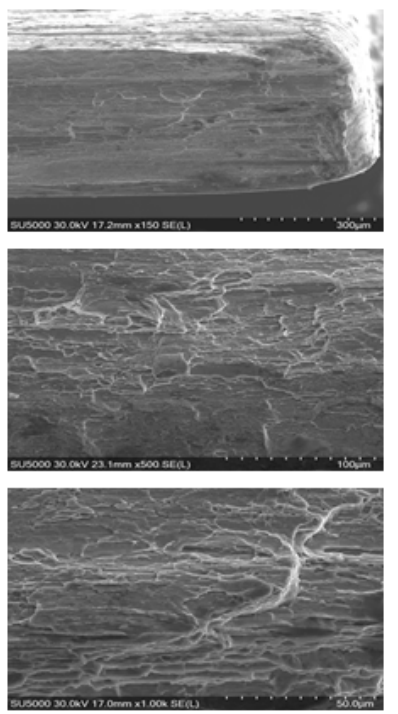

SEM Fe-14Cr ODS for $500{ }^{\circ} \mathrm{C}$ grain shape, some particular texture characteristics, decohesion of the grain boundaries, segregated impurity atoms and inclusions could lead to this delaminating. These factors may act individually or simultaneously.

\section{Conclusions}

The paper presents some aspects from the experimental activity performed by RATEN ICN in the framew ork of the FP7 European MatISSE Project. Its objective is the characterization of mechanical properties of candidate materials for a structural component in the generation IV reactors.

RATEN ICN commitment included the determination of the mechanical properties of the Fe-9Cr ODS and Fe-14Cr ODS alloys provided for the investigation in this project. It has been decided that the testing method be nonstandardized test Ring Tension Test and the test conditions comprise mechanical tests at both room temperature and at $500^{\circ} \mathrm{C}$. 
Experimental tests revealed the different behaviour of materials under the same conditions of temperature such that the Fe-14Cr ODS steel has lower tensile strength than steel Fe-9cr ODS at the same temperature. Also, the tensile strength decreases for both materials relative to the temperature increase. Micro-structural investigations of the fracture surface by scanning electron microscopy put into evidence the characteristics of the two materials. Thus, Fe-9Cr ODS steel has a ductile fracture fashion while the Fe-14Cr ODS steel undergoes a predominant fracture through the cleavage phenomenon with small ductile areas. Also, one may observe differentaspects of the grains of the two materials. Following lamination process, Fe$14 \mathrm{Cr}$ ODS steel grains are elongated while Fe-9Cr ODS steel has more fine grains.

Continuing the experimental work, to evaluate mechanical properties of ODS alloys provided under the project comprise two directions:

-The first direction represents the need to improve statistical mechanical tests results using the Ring Tension Test method by repeating tests at temperatures of interest in the operation of generation IV reactors.

-The second direction aims to continue the mechanical investigation using the Pin Load Test method to determine the fracture toughness $\left(\mathrm{K}_{\mathrm{lc}}\right)$ of the material.

Acknowledgment: This work was accomplished thanks to the financial support from the European Commission, in the framework of the MatISSE project under Grant No. 604862 and contributes to the Joint Programme on Nuclear Materials (JPNM) of the European Energy Research Alliance (EERA). We also express our gratitude to the CEA France partners, for providing the ODS tube samples and some material information.

\section{References}

1. T. LEBLOND et. all. ,Comparison of properties of extruded steels reinforced or not by Y-Ti-O nanoparticles, 3rd Int Conference on Thermochemical Processing of steels, Padova, 10-12 Sept. 2008
2. G. SUNDARARAJAN et. all. ,Development of $9 \mathrm{Cr}$ ferritic-martensitic and $18 \mathrm{Cr}$ ferritic oxide dispersion strengthened steels, Current Science, vol. 105, No.8, 25 oct. 2013

3. DUMITRESCU, I.M., MiHALACHE, M., ABRUdEANU, M., Rev. Chim.(Bucharest), 66, no.2, 2015, p. 290.

4. DUMITRESCU, I., MIHALACHE, M., DINU, A., MELEG, T., OHAI, D., ABRUDEANU, M., Rev. Chim.(Bucharest), 66, no. 3, 2015, p. 316.

5. M. LE FLEM ET. all. ,French R\&D on materials for the core components of SFRs, FR13, 4-7 March. 2013

6. ABRUDEANU M., ARCHAMBAULT P., Conference Zr-95, Saclay, France, 1995, p. 303.

7.ABRUDEANU M., ARCHAMBAULT P., PETOT-ERVAS G, PETRESCU N., PETRESCU M., Proceeding of the Second International Conference Held at Selwyn College University of Cambridge, IM- ISBN 0901 716502, 1993, p. 387.

8.ABRUDEANU M., PETRESCU N., International Conference of Diffusion and Defects in Solids DD91, Academy of Sciences, Moscou- URSS, 75, 1991, p. 84.

9. T. LEBLOND et. all. ,Comparison of properties of extruded steels reinforced or not by Y-Ti-O nanoparticles, 3rd Int. Conference on Thermomechanical Processing of steels, Padova, 10-12. Sept. 2008

10. DINU, A., ABRUDEANU, M., Rev. Chim. (Bucharest), 58, no. 8, 2007, p.751.

11. ARCHAMBAULT P., ABRUDEANU M., COLLERET B., J. Nucl. Mater, 200, Issue 2, 1993, p. 162.

12. AL. NITU et. all. , Prospective study for RTT on ODS Internal Research Report, 2015

13. AL. NITU et. all. , The non-standard tests on gen IV materials Internal Research Report, 2016

14. PARKER, W. J., JENKINS, R. J., BUTLER, C. P., and ABBOTT, G. L., J. Appl. Phys., 9, no. 32, 1979 (1961).

15. WATT, D. A., Br. J. Apply. Phys., 17, 1966, p. 231.

16. PEI HE, On the structure-property correlation and the evolution of nanofeatures in 12-13\% Cr Oxide Dispersion Strengthened Ferritic Steels, KIT Scientific Publishing, Karlsruhe, 2014

17.SWAIN M.V., J OHNSON L.F., SYED R., HASSELMAN D.P.H., J. Mater. Sci. Lett., 5, 1986, p. 799.

$\overline{\text { Manuscript received: } 30.08 .2017}$ 